\title{
Loss of Gaq impairs regulatory B-cell function
}

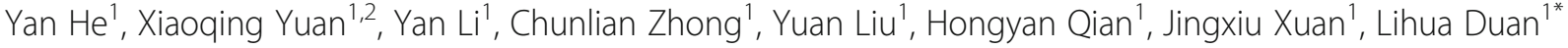 \\ and Guixiu Shi ${ }^{*}$
}

\begin{abstract}
Background: Recent studies have shown a crucial role of Gaq in immune regulation, but how Gaq modulates regulatory B-cell (Breg) function is still unclear. We address this here.

Methods: $\mathrm{CD} 19^{+} \mathrm{IL}-10^{+}$Bregs of wild-type (WT) and $\mathrm{Gnaq}^{-/-}$mice were analyzed by flow cytometry after stimulation by lipopolysaccharide. The WT and $\mathrm{Gnaq}^{-1-}$ Bregs were isolated and cocultured with WT $\mathrm{CD}^{+} \mathrm{CD}_{2} 5^{-} \mathrm{T}$ cells in the presence of T-activator, and the proliferation of T cells and differentiation of regulatory $T$ cells (Tregs) were analyzed by flow cytometry. We used inhibitors of PI3 kinase (PI3K), extracellular regulated protein kinases 1/2 (Erk1/2), and p38 mitogen-activated protein kinase (p38 MAPK) to detect the pathways involved in the regulation of Gaq on Breg differentiation, which were confirmed by western blot analysis. Furthermore, the expression level of Gaq was assessed by quantitative real-time PCR in peripheral blood mononuclear cells (PBMCs) from healthy controls and rheumatoid arthritis patients. The frequency of $\mathrm{CD} 19^{+} \mathrm{CD} 24^{\text {hi }} \mathrm{CD} 38^{\text {hi }} \mathrm{B}$ cells in PBMCs was detected by flow cytometry, and the association of the Gaq mRNA expression level and the frequency of $C D 19^{+} C D 24^{\text {hi }} C D 38^{\text {hi }} B$ cells was analyzed by Spearman test.
\end{abstract}

Results: The differentiation of $\mathrm{CD} 19^{+} \mathrm{IL}-10^{+}$Bregs was inhibited in the $\mathrm{Gnaq}^{-1-}$ mice. In addition, Gaq depletion showed an impaired suppressive function of Bregs on T-cell proliferation, which might be due to the decreased Treg expansion. Mechanically, our data demonstrated that the PI3K, Erk1/2, and p38 MAPK signaling pathways were required for regulation of Gaq on Bregs, and blockage of these signaling pathways impaired Breg differentiation. Consistent with our previous studies, we also found a decreased frequency of CD $19^{+}$CD $24^{\text {hi }}$ CD $38^{\text {hi }}$ Bregs in rheumatoid arthritis patients. As expected, a significantly positive correlation was investigated between

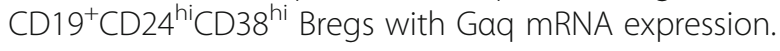

Conclusions: Our results indicate that Gaq plays a critical role in the differentiation and immunosuppression of Bregs, and it may provide a new therapeutic target for autoimmune diseases.

Keywords: Gaq, Regulatory B cells, IL-10, Regulation

\section{Background}

B cells are best known for their capacity to produce antibodies. In addition, they also exert a variety of other functions during the immune response, including antigen presentation and production of various cytokines, which are involved in the early and late stages of T-cell-mediated immune responses [1]. However, B-cell-deficient mice were observed to be susceptible to experimental autoimmune

\footnotetext{
*Correspondence: Ih-duan@163.com; gshi@xmu.edu.cn

${ }^{1}$ Department of Rheumatology and Clinical Immunology, The First Affiliated Hospital of Xiamen University, Xiamen, China

Full list of author information is available at the end of the article
}

encephalitis (EAE), and to be unable to recover from it [2]. Furthermore, adoptive transfer of $\mathrm{IL}_{-} 10^{+} \mathrm{B}$ cells can suppress inflammation of EAE [3]. A new population of B cells, regulatory B cells (Bregs), has increasingly gained attention for restraining inflammation $[4,5]$. Bregs can suppress the differentiation of $\mathrm{T}$ helper 1 (Th1) and $\mathrm{T}$ helper 17 (Th17) cells, and promote regulatory T-cell (Treg) induction [6, 7]. It was also reported that Bregs support the maintenance of invariant nature killer $\mathrm{T}$ (iNKT) cells [8]. Bregs have been shown to inhibit autoreactive and pathogen-driven immune response mainly through the production of interleukin-10 (IL-10), interleukin-35

(C) The Author(s). 2018 Open Access This article is distributed under the terms of the Creative Commons Attribution 4.0 International License (http://creativecommons.org/licenses/by/4.0/), which permits unrestricted use, distribution, and 
(IL-35), and transforming growth factor beta (TGF- $\beta$ ) [9]. Until now, the production of immune-suppressive cytokine IL-10 was thought to be a hallmark of Breg function [10]. In some human autoimmune diseases, it has been reported that Breg function is impaired and does not prevent the development of human autoimmune diseases, such as RA [7], relapsing-remitting multiple sclerosis [11], systemic lupus erythematosus (SLE) [12], and so on [13]. However, the mechanism of impaired Breg function in autoimmune diseases remains unclear.

The heterotrimeric guanine nucleotide-binding proteins ( $G$ proteins) are important signal transducers, which when attached to the cell surface plasma membrane receptors, G protein-coupled receptors (GPCRs), can communicate with signals from a large number of hormones, neurotransmitters, chemokines, sensory stimuli, and autocrine and paracrine factors. The heterotrimeric $\mathrm{G}$ proteins are composed of three subunits $(\alpha, \beta$, and $\gamma$ subunits) that cycle between inactive and active signaling states in response to guanine nucleotides $[14,15]$. On the basis of downstream signaling targets of $\alpha$ subunits, these $\alpha$ subunits are divided into four classes:

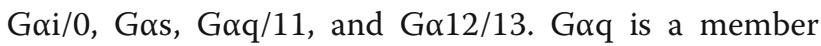
of the Goq/11 subfamily encoded by GNAQ [16]. Goq is ubiquitously expressed in mammalian cells and nearly $40 \%$ of all GPCRs rely upon Goq family members to stimulate inositol lipid signaling [15]. It is well known that Goq plays an essential role in the nervous system, endocrine system, and cardiovascular system [16-20]. Many studies have also established the physiological importance of Goq in the immune system. A previous study showed that Gaq-deficient $\left(\mathrm{Gnaq}^{-/-}\right)$mice exhibited impaired eosinophil recruitment to the lung after antigenic challenge, probably due to an impaired production of granulocyte macrophage colony stimulating factor (GM-CSF) by resident airway leukocytes [21]. Our previous study reported that $\mathrm{Gnaq}^{-/-}$ dendritic cells were defective in migrating from the skin to draining lymph nodes after fluorescein isothiocyanate sensitization, and $\mathrm{Gnaq}^{-/-}$monocytes were defective in migrating from the bone marrow into inflamed skin after contact sensitization [22]. The functional involvement of Goq in TCR-induced immune responses was also investigated [23]. In addition, Gnaq ${ }^{-/-}$chimeras could spontaneously develop manifestations of systemic autoimmune disease with high titer antinuclear antibody and inflammatory arthritis, which was observed in our previous study [24]. In humans, our previous work also showed that Goq mRNA expression was decreased in peripheral blood lymphocyte cells (PBMCs) and T cells from SLE patients compared to that from healthy individuals. What is more, the Goq expression in T cells from SLE patients was associated with disease severity, the presence of lupus nephritis, and expression of Th1, Th2, and Th17 cytokines [25]. We also found that B cells from mice lacking the Goq subunit of trimeric $G$ proteins have an intrinsic survival ad-

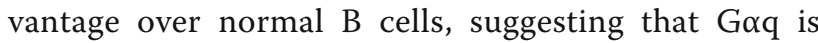
critically important for maintaining control of peripheral B-cell tolerance induction and repressing autoimmunity [24]. Whether Goq regulates Breg function is still unknown.

In this study, we found a critical role of Gaq in Breg differentiation and $\mathrm{Gnaq}^{-/-}$Bregs showed an impaired suppressive function on T-cell proliferation. Our human data also showed that the decreased frequency of Bregs showed a significantly positive correlation with Goq mRNA expression in RA patients. Taken together, our work reveals a novel function of Goq in regulating Breg function.

\section{Methods}

\section{Patients and controls}

Peripheral blood was obtained from 34 RA patients and 24 healthy controls from the inpatient clinic of the Department of Rheumatology, The First Affiliated Hospital of Xiamen University, Xiamen, China. The criteria used for RA diagnosis were based on those of the American Rheumatism Association (1987) [26] and the new criteria from the ACR/EULAR (2010) [27]. Goq mRNA expressions were detected by RT-PCR, the frequency of $\mathrm{CD} 19^{+} \mathrm{CD} 24^{\text {hi }} \mathrm{CD} 38^{\text {hi }} \mathrm{B}$ cells in PBMCs was detected by flow cytometry, and the association of Goq mRNA expression level and frequency of $\mathrm{CD} 19^{+} \mathrm{CD} 24^{\mathrm{hi}} \mathrm{CD} 38^{\mathrm{hi}}$ $\mathrm{B}$ cells was studied. The clinical characteristics of the RA patients are summarized in Table 1. Informed consent was obtained from all recruits to this study. This study was approved by the Ethics Committee of the First Affiliated Hospital of Xiamen University in accordance with the World Medical Association Declaration of Helsinki.

Table 1 Demographic data and clinical characteristics of RA patients in the study

\begin{tabular}{lll}
\hline Characteristic & RA $(n=34)$ & $\mathrm{HC}(n=24)$ \\
\hline Age (years), mean (range) & $56(34-78)$ & $45(29-68)$ \\
Sex $(n)$, female/male & $26 / 8$ & $17 / 7$ \\
CRP (mg/L), mean (range) & $30.35(0.5-75.1)$ & \\
ESR (mm/h), mean (range) & $47.29(7-117)$ & \\
RF (IU/ml), mean (range) & $223.35(9.69-991)$ & \\
Anti-CCP (RU/ml), mean (range) & $52.50(1-200)$ & \\
$\begin{array}{l}\text { Tender joint count, mean (range) } \\
\text { of 68 joints }\end{array}$ & $6.35(0-26)$ & \\
$\begin{array}{l}\text { Swollen joint count, mean (range) } \\
\text { of 68 joints }\end{array}$ & $4.47(0-22)$ & \\
\hline RA rheumato ath & & \\
\end{tabular}

$R A$ rheumatoid arthritis, $H C$ healthy controls, CRP C-reaction protein, ESR erythrocyte sedimentation rate, $R F$ rheumatoid factor, anti-CCP anti-cyclic citrullinated peptide antibody 


\section{Animals}

All experimental procedures involving mice were approved by the institutional animal care committee of Xiamen University. C57BL/6 J (B6) mice were purchased from Xiamen University Laboratory Animal Center. C57BL/6 J (B6) mice and $\mathrm{Gnaq}^{-/}(n>8$ backcrossed to C57BL/6 J) mice were bred in Xiamen University Laboratory Animal Center. The mice used in this study were 6-8 weeks age.

\section{Cell isolation}

The purification of $\mathrm{CD} 4^{+} \mathrm{CD} 25^{-} \mathrm{T}$ cells from the spleen of mice was performed using the $\mathrm{CD}^{+} \mathrm{CD} 25^{-} \mathrm{T}$ Cell Isolation Kit (Miltenyi Biotec, Bergisch-Gladbach, Germany), LS Columns (Miltenyi Biotec), and MidiMACS ${ }^{\mathrm{TM}}$ Separators (Miltenyi Biotec) according to the manufacturer's instructions. Briefly, $1^{*} 10^{7}$ cells from the mice spleen were stained with biotin-antibody cocktail in buffer (PBS/2 mM EDTA/0.5\% BSA) for $5 \mathrm{~min}$ at $4{ }^{\circ} \mathrm{C}$. After that, the anti-Biotin MicroBeads and CD44 MicroBeads were sequentially added and incubated for $10 \mathrm{~min}$ at $4{ }^{\circ} \mathrm{C}$.Cells were washed, centrifuged, and resuspended in $0.5 \mathrm{ml}$ of buffer, and applied onto the column. The CD $4^{+} \mathrm{CD} 25^{-} \mathrm{T}$ cells in flow-through fluids were collected. The isolation of $B$ cells and Tregs from the spleen of mice was performed using the corresponding Pan B Cell Isolation Kit II (Miltenyi Biotec) and the CD $4^{+} \mathrm{CD} 25^{+}$Regulatory T cell Isolation Kit (Miltenyi Biotec) according to the manufacturer's instructions. Purity of the target cells was > 90\% in all experiments assessed by flow cytometry. CD $1 \mathrm{~d}^{\text {hi }} \mathrm{CD} 5^{+}$ $B$ cells were isolated using a MoFlo High-Performance Cell Sorter (Beckman Coulter, Fullerton, CA, USA) with purities of 90-95\%. Human PBMCs were isolated from $4 \mathrm{ml}$ sodium heparin-treated venous blood samples by Ficoll density-gradient centrifugation using Lymphoprep ${ }^{\text {тм }}$ (Axis-Shied PoC AS, Oslo, Norway). Washed and resuspended, the PBMCs were cryopreserved for future real-time polymerase chain reaction.

\section{Cell culture}

Purified B cells were planted in complete RPIM 1640 with $2.05 \mathrm{mM}$ L-glutamine (GE Healthcare Life Sciences, Logan, UT, USA) supplement with 10\% fetal bovine serum (PAN Seratech, Aidan Bach, Germany) and maintained in standard cell culture environment (95\% humidity, 5\% $\mathrm{CO}_{2}$ at $37^{\circ} \mathrm{C}$ ). For Breg induction, B cells were stimulated with LPS (Escherichia coli 0111:B4; Sigma-Aldrich, St. Louis, MO, USA) $(10 \mu \mathrm{g} / \mathrm{ml})$ for $48 \mathrm{~h}$. PMA $(50 \mathrm{ng} / \mathrm{ml})$, ionomycin (250 ng/ml) (Sigma-Aldrich), and brefeldin A $(10 \mu \mathrm{g} / \mathrm{ml})$ (BD Biosciences, San Jose, CA, USA) were added for the last $5 \mathrm{~h}$ of culture before flow cytometry. For analysis of $\mathrm{CD}_{4}^{+}$T-cell proliferation and Treg differentiation, purified LPS-induced Bregs from the spleen of WT mice or $\mathrm{Gnaq}^{-/-}$mice and sorted CD4 ${ }^{+} \mathrm{CD} 25^{-}$T cells from the spleen of WT mice were 1:1 cocultured and activated with Dynabeads ${ }^{\mathrm{Tm}}$ Mouse T-Activator CD3/CD28 (Life Technologies AS, Oslo, Norway) at a bead-to-cell ratio of 1:2 in $200 \mu \mathrm{l}$ medium in a 96-well U-bottom plate for $72 \mathrm{~h}$.

\section{Antibodies}

Anti-human antibodies included: anti-CD19-FITC from BD Biosciences; anti-CD24-PE (ML5) and anti-CD38-PE /Cy7 (HIT2) from Biolegend (San Diego, CA, USA); and Human FcR Binding Inhibitor from eBioscience (San Diego, CA, USA). Anti-mouse antibodies included: anti-CD4-FITC (RM4-5), anti-CD19-PE/Cy5, anti-CD19-APC (6D5), anti-CD25-APC (3C7), anti-IL-10-PE (JES5-16E3), PE Rat IgG2b, $\kappa$ Isotype Ctrl (RTK4530), and anti-PD-L1-APC (10.F.9G2) from Biolegend; anti-CD1d-PE (1B1), anti-CD5FITC (53-7.3), anti-CD16/CD32 (mouse Fc block), antiAnnexin-V-APC, and 7-AAD from BD Biosciences; and anti-CD25-PE/Cy5.5 (PC61.5), anti-Foxp3-PE (NRRF-30), anti-TLR4-Alexa Fluor ${ }^{\circ}$ 488(UT41), and anti-FasL-FITC (MFL3) from eBioscience. Phosho-p38 MAPK (Thr180/ Tyr182) (28B10) mouse mAb, p38 MAPK (D13E1) XP rabbit mAb, phosho-p44/42 MAPK (Erk1/2) (Thr202/ Tyr204) (D13.14.4E) $\mathrm{XP}^{\oplus}$ rabbit mAb, p44/42 MAPK (Erk1/2) (137F5) rabbit mAb, phosho-PI3K p85 (Tyr458)/ p55 (Tyr199) antibody, PI3K p85 $\alpha$ (6G10) mouse mAb, phospho-STAT1 (Thr701) (58D6) rabbit mAb, STAT1 (D1K9Y) rabbit $\mathrm{mAb}, \mathrm{GAPDH}$ (14C10) rabbit $\mathrm{mAb}$, $\beta$-Tubulin (9F3) rabbit $\mathrm{mAB}$, anti-mouse IgG, HRP-linked antibody, anti-rabbit IgG, and HRP-linked antibody were obtained from Cell Signaling Technology (MA, USA); and anti-MyD88 antibody was obtained from Abcam (Cambridge, UK).

\section{Real-time polymerase chain reaction}

Total RNA was extracted from PBMCs with TriPure Isolation Reagent (Roche Diagnostics $\mathrm{GmbH}$, Mannheim, Germany) and the concentration of RNA was determined by measuring the absorbance at $260 \mathrm{~nm}$ in a UV-Vis spectrophotometer (Quawell, San Jose, CA, USA). Reverse transcription was performed by the Bio-Rad Systems (Bio-Rad, Hercules, CA, USA) according to standard protocols using the Transcriptor First Strand cDNA Synthesis Kit (Roche Diagnostics GmbH). The expression level of Goq was measured by real-time quantitative PCR. $\beta$-actin was simultaneously amplified and used as an internal control. The primer sequences were as follows: $\beta$-actin forward, 5'-AGAAAATCT GGCACCACACC-3'; $\beta$-actin reverse, 5'-AGAGGCG TACAGGGATAGCA-3'; Goq forward, 5'-GTTGAT GTGGAGAAGGTGTCTG-3'; and Goq reverse, 5'-G TAGGCAGGTAGGCAGGGT-3'. Amplification was performed with the 7500 Real Time PCR Systems (Applied Biosystems, CA, USA). Gene expression levels 
were normalized by comparing to $\beta$-actin and relative expression was calculated by the $2^{-\Delta \Delta \mathrm{Ct}}$ method.

\section{Enzyme-linked immunosorbent assay}

The concentration of mouse IL-10 (BD Biosciences), IL-35 (Wuhan Huamei, China), TGF- $\beta$, IL-23 (Invitrogen, Carlsbad, CA, USA), and IL-6 (R\&D, Minneapolis, MN, USA) were measured using commercially available ELISA kits according to the manufacturer's instructions. Absorbance at $450 \mathrm{~nm}$ was measured with an ELISA microplate reader (Molecular Devices, Sunnyvale, CA, USA).

\section{Flow cytometry}

Fc receptors were blocked with mouse Fc block and the dead cells were detected using Fixable Viability Dye eFlour $^{\text {Ta }} 506$ or 510 (eBioscience) before cell surface staining. For Breg staining, CD19-FITC or PE/Cy5, CD24-PE, CD38-PE/Cy7, CD1d-PE, and CD5-FITC $\mathrm{mAbs}$ were used. For intracellular IL-10 staining, cells were stained with CD19-PE/Cy5 or APC mAbs. Cells were washed, fixed with IC Fixation Buffer (eBioscience), permeabilized with Permeabilization Buffer (eBioscience), and stained with IL-10-PE. For Treg staining, cells were stained with combinations of CD4-FITC and CD25-PE/Cy5.5 or APC mAbs, fixed and permeabilized with Fixation/Permeabilization solution (eBioscience) and Permeabilization Buffer, and stained for detection of intracellular Foxp3-PE mAbs. For apoptotic cell detection, cells were washed twice with cold PBS and then resuspended in $1 \times$ Binding Buffer (BD Biosciences), and then the cells were stained with CD4-FITC, APC Annexin-V, and 7-AAD and incubated for $15 \mathrm{~min}$ at RT in the dark. Last, $400 \mu \mathrm{l}$ of $1 \times$ Binding Buffer was added. Data were acquired using Cytomic FC500 or Cytoflex (Beckman Coulter) and analyzed using CXP Analysis and Cytexpert (Beckman Coulter).

\section{Western blot analysis}

Single-cell suspensions were lysed after stimulation in cOmplete Lysis-M (Roche Diagnostics $\mathrm{GmbH}$ ) containing protease inhibitor cocktail (Roche Diagnostics $\mathrm{GmbH}$ ) and phosphatase inhibitor cocktail (Roche Diagnostics $\mathrm{GmbH}$ ) for $10 \mathrm{~min}$ with gentle shaking. The lysates were centrifuged at $14,000 \times g$ for $15 \mathrm{~min}$, and frozen at $-80^{\circ} \mathrm{C}$ until use. For western blotting assays, the protein concentrations were determined using the BCA Protein Assay Kit (Thermo Scientific, Rockford, IL, USA), and equal amounts of protein $(20 \mu \mathrm{g})$ per lane were separated by $10 \%$ SDS-PAGE gels and transferred to PVDF membranes. Membranes were blocked and then probed with primary antibodies against p-p38 MAPK (1:1000), p-Erk1/2 (1:2000), p-PI3K (1:1000), p-STAT1 (1:1000), or MyD88 (1:1000) at $4{ }^{\circ} \mathrm{C}$ overnight. After washing, the membranes were incubated with the appropriate
HRP-conjugated secondary antibodies for $1 \mathrm{~h}$ at room temperature. After extensive washing, signals were visualized using the chemiluminescent HRP substrate system (Millipore, Billerica, MA, USA). Band quantification was performed on the Molecular Imager ${ }^{\circ}$ ChemiDoc $^{\text {Tw }}$ XRS+ system with Image Lab ${ }^{\text {Tw }}$ Software (Bio-Rad, Hercules, CA, USA). Thereafter, membranes were stripped with stripping buffer before reprobing with anti-p38 MAPK (1:1000), Erk1/2 (1:1000), PI3K (1:1000), and STAT1 (1:1000) to ensure equal loading. GAPDH or $\beta$-Tubulin was also detected as the loading control. The level of protein phosphorylation was normalized to the loading control (total protein).

\section{Statistical analysis}

All data were obtained from at least three independent experiments and shown as mean \pm standard deviation (SD). All data were analyzed using GraphPad Prism 5.01 software (GraphPad, San Diego, CA, USA). Statistical significance was determined by Student's $t$ test and the Mann-Whitney $U$ test. Correlation was analyzed using Spearman's test. A probability value of $p<0.05$ was considered statistically significant.

\section{Results}

\section{Gaq regulates Breg differentiation}

We and others have reported that Goq plays a critical role in immune disorders via regulating immune cell function. Recently, a crucial role of Bregs has been described in many studies. Nevertheless, whether Goq regulates Breg function remains unknown. The $G n a q^{-/-}$ mice were used to address this question. The flow cytometry analysis showed that there was no difference between WT and $\mathrm{Gnaq}^{-/-}$mice on the percentage of CD $19^{+} \mathrm{CD} 1 \mathrm{~d}^{\text {hi }} \mathrm{CD}^{+}$Bregs (Fig. 1a, b) and CD $19^{+} \mathrm{IL}-10^{+}$ Bregs (Fig. 1d, e), both of which are considered Breg markers in mice [9]. Additionally, no marked difference in the absolute number of Bregs was observed (Fig. 1c, f). Interestingly, a significantly higher expression of IFN- $\gamma$ and IL-17 was observed in $\mathrm{Gnaq}^{-/-} \mathrm{CD} 19^{+} \mathrm{CD} 1 \mathrm{~d}^{\mathrm{hi}} \mathrm{CD} 5^{+}$ Bregs (see Additional file 1: Figure S1A-D). Although increased production of IFN- $\gamma$ by $\mathrm{Gnaq}^{-/-}$Bregs was observed, the STAT1 phosphorylation after LPS stimulation showed no difference between WT and $\mathrm{Gnaq}^{-/-}$Bregs (see Additional file 1: Figure S1E). In order to address whether Goq has a role in regulating Breg differentiation, splenic B cells were isolated from WT and $\mathrm{Gnaq}^{-/-}$mice, and then stimulated with lipopolysaccharide (LPS) for $48 \mathrm{~h}$, which was shown to induce IL- $10^{+}$Breg differentiation [4]. After stimulation, the percentage of $\mathrm{CD} 19^{+} \mathrm{IL}-10^{+}$Bregs was significantly lower in $\mathrm{Gnaq}^{-/-}$mice (Fig. 1g, h). In addition, the expression of IL-10 in culture supernatant was also lower in $\mathrm{Gnaq}^{-1-}$ mice when compared with that in WT mice 


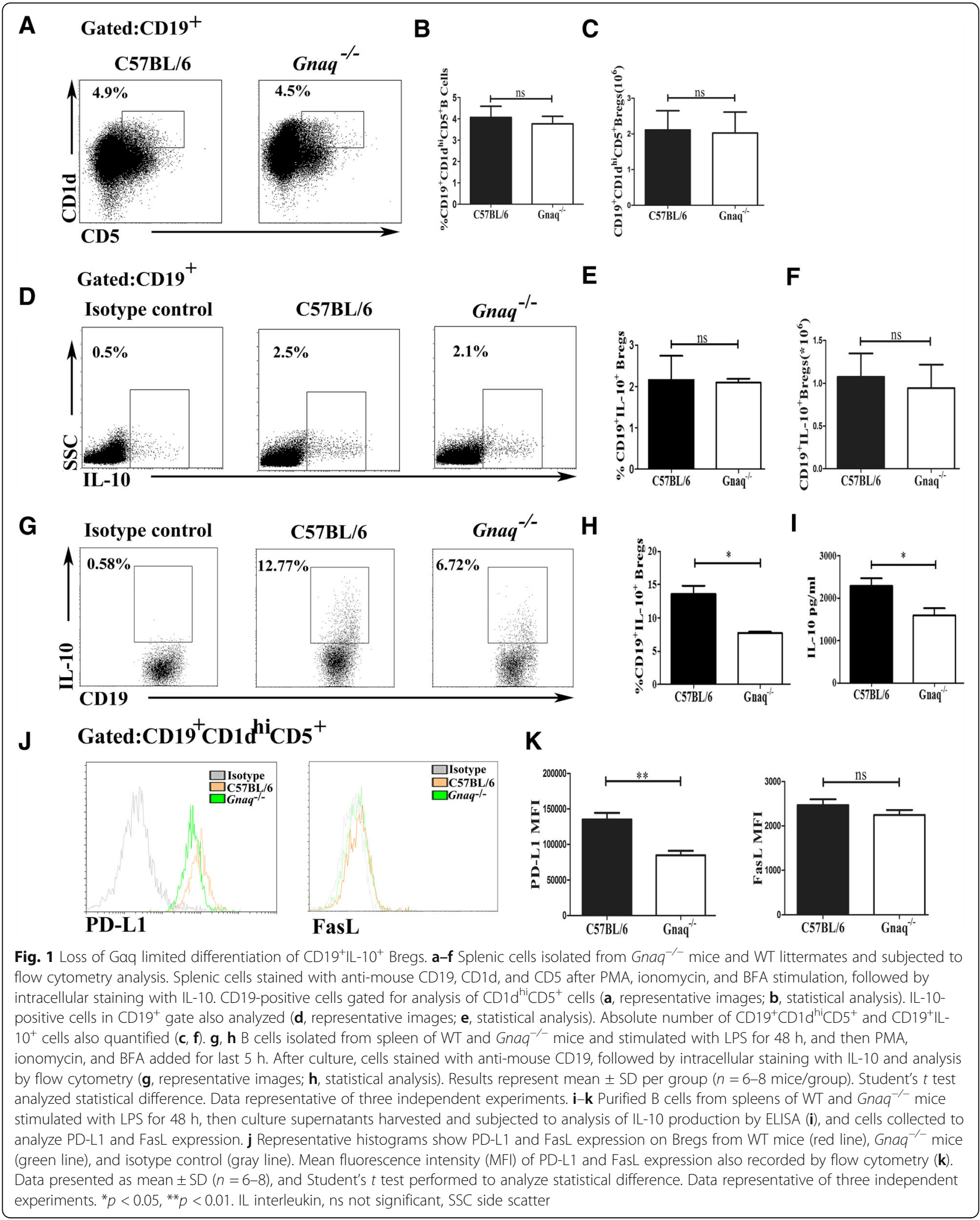

(Fig. 1i). The IL-17 expression was slightly decreased in both groups, which might due to Breg differentiation by LPS stimulation (see Additional file 1: Figure S1F).
Due to a critical role of IL-35 and TGF- $\beta$ in Breg suppressive function, we also detected the expression of IL-35 and TGF- $\beta$. TGF- $\beta$ production was lower in 
$\mathrm{Gnaq}^{-/-}$mice, while IL-35 expression was comparable with that in WT mice (see Additional file 2: Figure S2). Additionally, the inhibitory ligand PD-L1 on Gnaq ${ }^{-/-}$ Bregs was also decreased. No different change was observed in FasL expression (Fig. 1j, k).

To rule out the effect of cell death on the decreased percentages of $\mathrm{Gnaq}^{-/-}$Bregs after $48 \mathrm{~h}$ LPS stimulation, the rates of dead cells were analyzed in the WT and $\mathrm{Gnaq}^{-1-}$ Bregs. We found that Goq deficiency did not promote cell death, while a decreased rate of cell death in $\mathrm{Gnaq}^{-/-}$ Bregs was observed (Fig. 2a, b), which was in keeping with our previous published data [24]. Previous studies have shown the role of Toll-like receptors (TLRs) in B cell-mediated regulation [28-30]. Since we induced Bregs using LPS, the agonist of TLR4, we next detected TLR4 expression on both WT and $\mathrm{Gnaq}^{-1-}$ B-cell surfaces. As shown in Fig. 2, there was no difference between them.
Furthermore, myeloid differentiation primary response 88 (MyD88), a key signaling molecule downstream of TLRs, was also analyzed by immunoblotting. Consistently, no marked differences were observed (Fig. 2c, d). These data indicated that Goq has no effect on the TLR4/MyD88 signal pathway.

\section{Gaq is required for Breg immunosuppression}

To verify whether $\mathrm{Gnaq}^{-/-}$Bregs have an inhibitory effect on T-cell proliferation, $\mathrm{CD} 1 \mathrm{~d}^{\text {hi }} \mathrm{CD}^{+} \mathrm{B}$ cells were sorted from both WT and $\mathrm{Gnaq}^{-1-}$ mice, and then we cocultured with purified $\mathrm{CD} 4^{+} \mathrm{CD} 25^{-} \mathrm{T}$ cells from the WT mice for $72 \mathrm{~h}$ under the stimulation of Mouse T-Activator CD3/ CD28 Dynabeads ${ }^{\mathrm{Tx}}$. Although it was weaker than that of Tregs, the inhibitory effect of WT Bregs on T-cell proliferation was significantly strong when compared to that of $\mathrm{Gnaq}^{-/-}$Bregs (Fig. 3a-c). Furthermore, there was no

\section{A Gated:CD19 ${ }^{+}$IL-10 $10^{+}$ C57BL/6}

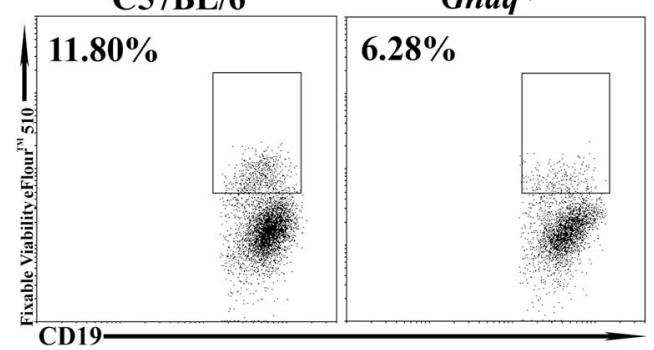

\section{C}

Gated:CD19 ${ }^{+}$

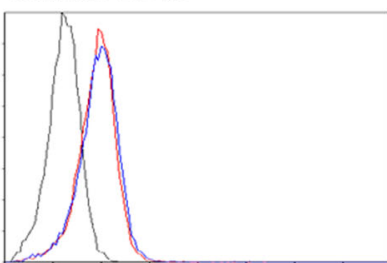

TLR4
B

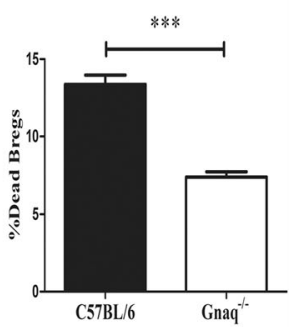

D

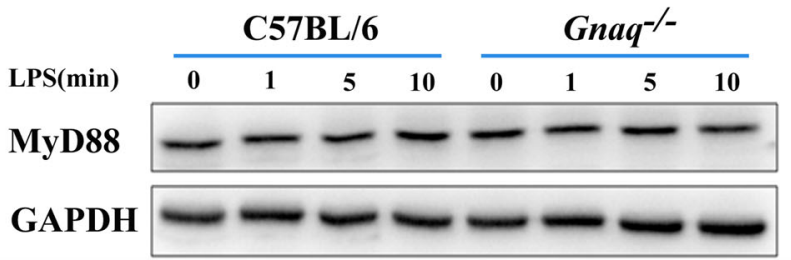

Fig. 2 Gaq deficiency did not affect TLR4 signaling in B cells. a, b B cells purified from WT and Gnaq ${ }^{-1-}$ mice stimulated with LPS for 48 h, and PMA, ionomycin, and BFA added for last 5 h. Fixable Viability Dye eFlour ${ }^{\mathrm{TM}} 510$ used to analyze B-cell death by flow cytometry. Data presented as mean \pm SD of five mice. Results shown are one from three independent experiments. Student's $t$ test analyzed statistical difference. ${ }^{* * *} p<0.001$. c Splenic cells from WT and Gnaq ${ }^{-/-}$mice stained with anti-mouse CD19 and anti-mouse TLR4, followed by flow cytometry analysis $(n=5)$. Representative histogram shown. Blue line, WT mice; red line, Gnaq ${ }^{-/-}$mice. Data representative of three independent experiments. d WT and $\mathrm{Gnaq}^{-1-}$ B cells treated with LPS, then harvested to analyze Myd88 expression by western blot analysis at indicated times. Data representative of three independent experiments. Breg regulatory B cell, IL interleukin, LPS lipopolysaccharide, MyD88 myeloid differentiation primary response 88 , TLR Toll-like receptor 
difference among control Bregs, WT Bregs, and $\mathrm{Gnaq}^{-1-}$ Bregs in the viability of T cells (Fig. 3d, e), which indicated that the different $\mathrm{T}$-cell proliferation was not due to different cell apoptosis. Previous studies have revealed that Bregs can restrain inflammation by promoting differentiation of Tregs [6, 7]. To evaluate the contribution of $\mathrm{G \alpha q}$ in this function of Bregs, we cocultured Bregs purified from WT or $\mathrm{Gnaq}^{-\prime-}$ mice with WT $\mathrm{CD} 4^{+} \mathrm{CD} 25^{-} \mathrm{T}$ cells. As expected, an increased frequency of $\mathrm{CD} 4^{+} \mathrm{CD} 25^{+} \mathrm{Foxp}^{+}{ }^{+}$Tregs was detected in the WT group after stimulation, whereas there was no significant change of Foxp3 expression in the $\mathrm{Gnaq}^{-/-}$ group when compared with the no Breg experimental group (Fig. 4a, b). Lots of studies have demonstrated that the cytokines IL-6, IL-23, and TGF- $\beta$ act a crucial role in the regulation of Treg differentiation. Next, we analyzed these cytokines in the supernatants of cocultured WT or $\mathrm{Gnaq}^{-/-}$Bregs with activated $\mathrm{CD} 4^{+} \mathrm{CD} 25^{-} \mathrm{T}$ cells. As expected, IL-6 was increased in $\mathrm{Gnaq}^{-/-}$Bregs, whereas TGF- $\beta$ production was decreased (Fig. 4c). Unfortunately, the IL-23 concentration was lower than the sensitivity of the test kit. These data showed that Goq modulated Breg immunosuppression by regulating Breg cytokine production, which might affect Treg differentiation.

\section{Involvement of PI3K, Erk1/2, and p38 MAPK pathways in the regulation of Gaq on Breg differentiation}

Numerous reports indicate that Goq was implicated in regulating the MAPK pathways, PI3K/Akt pathways, and PLC- $\beta$ activation $[15,31]$. Interestingly, these pathways were also involved in production of IL-10 [32]. Therefore, we supposed that there might be crosstalk between Goq and IL-10 signaling pathways. To address this hypothesis, we first confirmed these signal pathways in Breg differentiation. The differentiation of WT Bregs was significantly decreased in the presence of LY294002 (PI3K inhibitor), U0126 (Erk1/2 inhibitor), or SB203580 (p38 MAPK inhibitor). However, no significant changes were observed in $\mathrm{Gnaq}^{-/-}$Bregs (Fig. 5a, b), which may be related to a significantly reduced activation of these signaling pathways in $\mathrm{Gnaq}^{-/-}$Bregs. Consistently, we found that the levels of phospho-PI3K, phospho-Erk1/2, and phospho-p38 MAPK were lower after LPS stimulation in $\mathrm{Gnaq}^{-1-}$ B cells when compared with those in WT B cells (Fig. 5c, d). In conclusion, the decreased

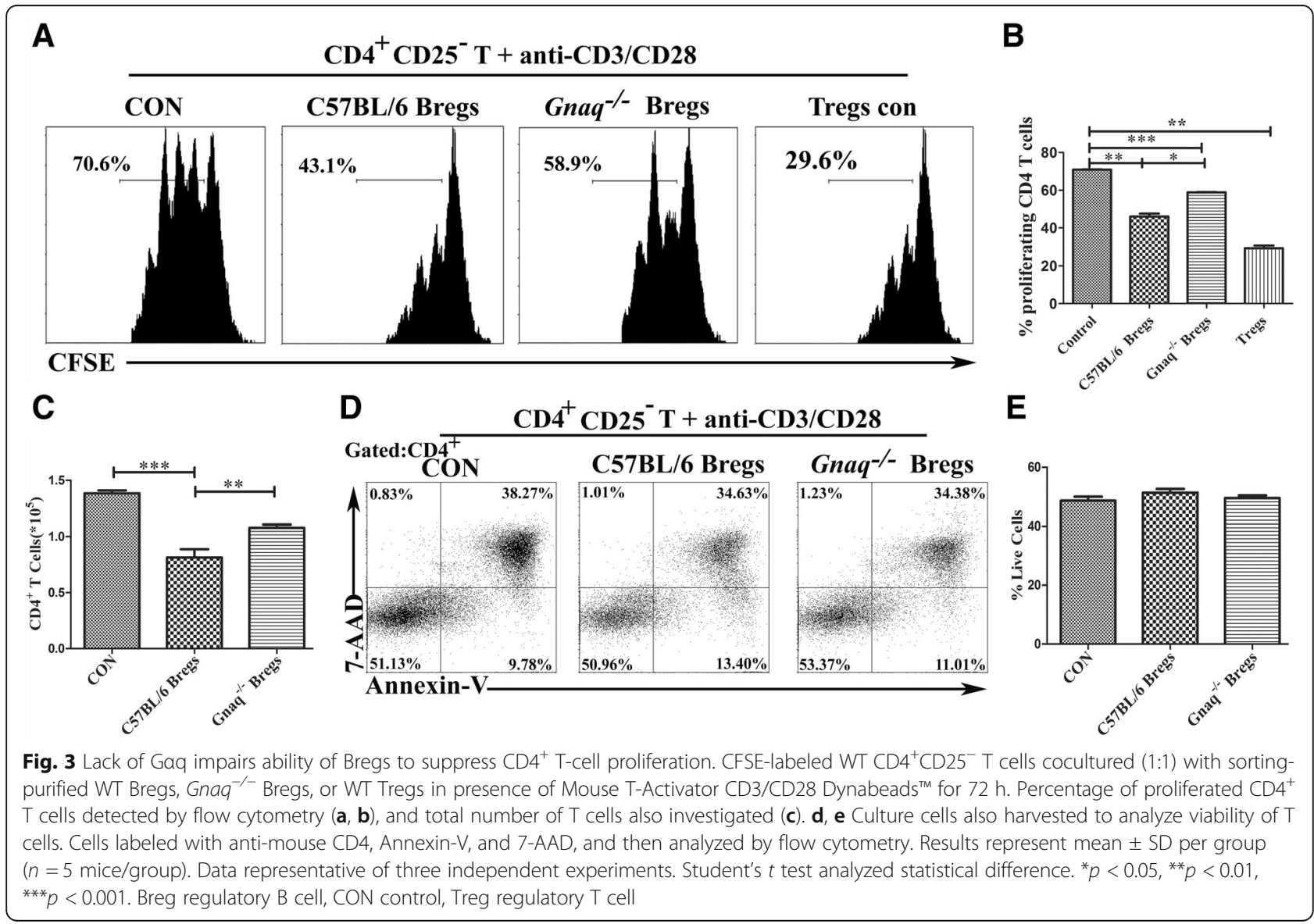




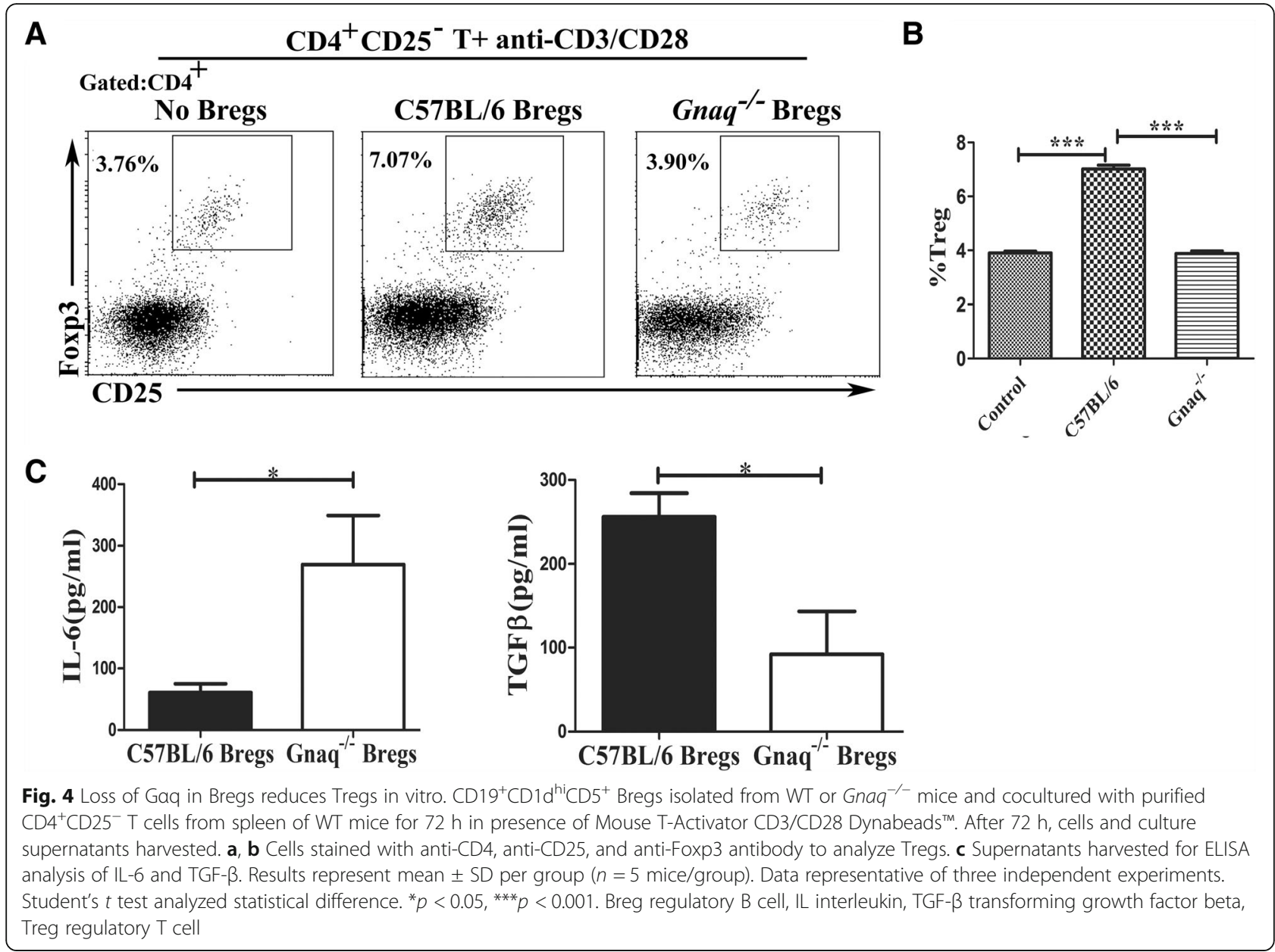

activation of PI3K, Erk1/2, and p38 MAPK contributed to the impaired differentiation of $\mathrm{Gnaq}^{-/-}$Bregs.

\section{Decreased frequency of $\mathrm{CD} 19^{+} \mathrm{CD} 24^{\mathrm{hi}} \mathrm{CD} 38^{\mathrm{hi}}$ Bregs was correlated with Gaq mRNA expression in RA patients}

Our presented experiments demonstrated that Goq exerted a role in regulating Bregs in mice. Previous studies have shown that the frequency of $\mathrm{CD} 19^{+} \mathrm{CD} 24^{\mathrm{hi}} \mathrm{CD} 38^{\mathrm{hi}}$ Bregs was decreased in RA patients. Human $\mathrm{CD} 19^{+} \mathrm{CD} 24^{\text {hi }} \mathrm{CD} 38^{\text {hi }}$ Breg subsets have been shown to maintain tolerance in immune disorders via the release of IL-10 [9]. Here, to further address the regulation of Goq in Breg function, we analyzed the correlation between Goq mRNA expression and frequency of regulatory $\mathrm{B}$ cells in PBMCs from RA patients. In comparison to $\mathrm{HC}$, a decreased frequency of $\mathrm{CD} 19^{+} \mathrm{CD} 24^{\mathrm{hi}} \mathrm{CD} 38^{\mathrm{hi}} \mathrm{B}$ cells was observed in RA patients (Fig. 6a, b), and the mRNA expression of Goq was also significantly lower in the RA group (Fig. 6c). Consistent with the animal results, we observed a significant positive correlation between the frequency of $\mathrm{CD} 19^{+} \mathrm{CD} 24^{\mathrm{hi}} \mathrm{CD} 38^{\mathrm{hi}} \mathrm{B}$ cells and the expression of Goq mRNA in PBMCs from patients with RA and HC (Fig. 6d). These data further confirm that
Gaq plays a critical role in immune tolerance via regulation of Bregs.

\section{Discussion}

Recent studies have shown that Bregs play a crucial role in autoimmune diseases through suppressing the differentiation of Th1 and Th17 cells, and promoting Treg induction [9]. However, the mechanism of Breg differentiation still remains unknown. Our previous studies demonstrated that Goq exerts an important role in immune regulation, including Th1 and Th17 function, while the role of Gaq in Breg regulation is still unclear. Here, we found that the differentiation and immunosuppressive effect of Bregs were inhibited in the $\mathrm{Gnaq}^{-1-}$ mice. In addition, our data demonstrated that the PI3K, Erk1/2, and p38 MAPK signaling pathways were involved in the regulation of Breg function by Goq. Furthermore, we also showed a decreased frequency of $\mathrm{CD} 19^{+} \mathrm{CD} 24^{\mathrm{hi}} \mathrm{CD} 38^{\text {hi }}$ Bregs in RA patients, which positively correlated with Goq mRNA expression. These data suggest that Goq was involved in the immune tolerance via regulating Breg function. 


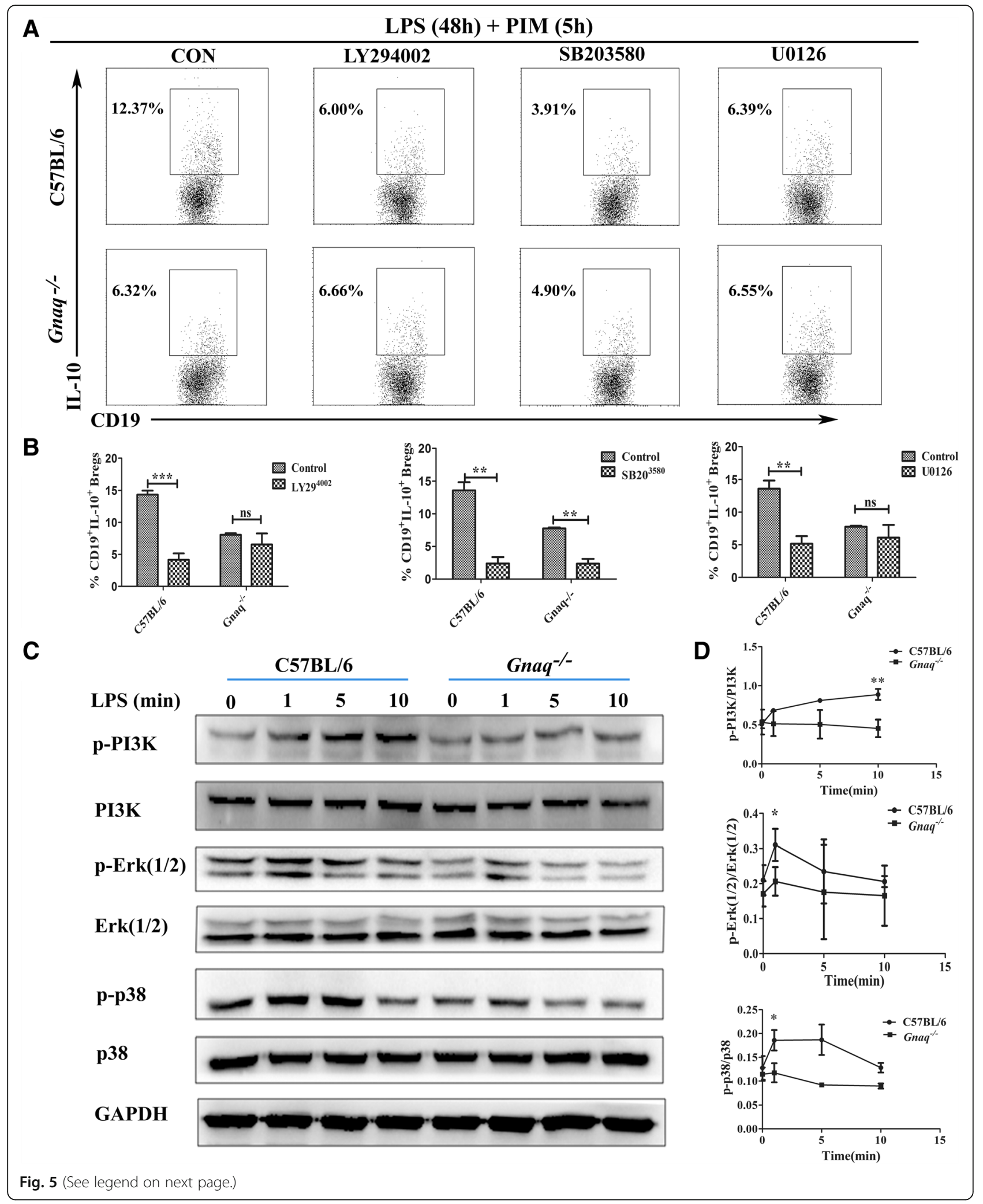


(See figure on previous page.)

Fig. 5 Decreased activation of PI3K, Erk1/2 MAPK, and p38 MAPK signaling pathways in Gnaq ${ }^{-/-}$Bregs. Isolated B cells from WT and Gnaq ${ }^{-/-}$mice

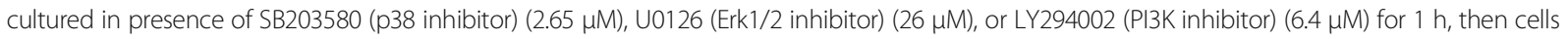
stimulated by LPS for $48 \mathrm{~h}$, and PMA, ionomycin, and brefeldin A added for last $5 \mathrm{~h}$ of culture. After culture, cells stained with anti-mouse CD19 and intracellular staining with IL-10, followed by flow cytometry analysis (a, representative images; b, statistical analysis). c Splenic B cells purified from WT and $\mathrm{Gnaq}^{-1-}$ mice and stimulated with LPS for 0-10 min. Protein from cell lysates exacted for analysis of phospho-PI3K, PI3K, phospho-Erk1/2, Erk1/2, phospho-p38 MAPK, and p38 MAPK by western blot analysis with specific antibodies individually. GAPDH used as loading control. $\mathbf{d}$ Protein expression levels quantified with Image Lab software. Ratios of phosphor-specific proteins versus total proteins obtained. Results represent mean \pm SD per group ( $n=4-5$ mice/group). Data representative of three independent experiments. Student's $t$ test analyzed statistical difference. ${ }^{*} p<0.05,{ }^{* * *} p<0.001$, ${ }^{* * *} p<0.001$. Breg regulatory B cell, CON control, Erk1/2 extracellular regulated protein kinases 1/2, GAPDH glyceraldehyde 3-phosphate dehydrogenase, IL interleukin, LPS lipopolysaccharide, ns not significant, PI3K PI3 kinase, PIM PMA/ionomycin/brefeldin A

The existence of B cells with a suppressive capacity was initially reported in the study of guinea pigs in the mid-1970s [33, 34]. In the past 40 years, lots of studies have been focused on regulatory $B$ cells and their mechanisms of action. Mizoguchi et al. [35] defined the B cells that produce IL-10 as regulatory B cells. Through producing IL-10, IL-35, and TGF- $\beta$, Bregs suppress immunopathology by prohibiting the expansion of pathogenic $T$ cells and maintaining the pool of Tregs [9]. In our study, we also showed that the impaired immunosuppression of $\mathrm{Gnaq}^{-/-}$Bregs might be due to the decreased production of IL-10 and TGF- $\beta$. Bregs have been considered an important immune regulatory cell in many diseases, such as EAE, type 1 diabetes, collagen-induced arthritis, inflammatory bowel diseases, lupus, and so on [36]. Similarly, CD $19^{+} \mathrm{CD} 24^{\text {hi }} \mathrm{CD} 38^{\text {hi }} \mathrm{B}$ cells, which were considered Bregs in human, can limit the differentiation of naïve $\mathrm{CD} 4^{+} \mathrm{T}$ cells into $\mathrm{Th} 1$ and Th17 populations, and maintain Treg function [7]. RA patients with active disease have reduced numbers of $\mathrm{CD} 19^{+} \mathrm{CD} 24^{\mathrm{hi}} \mathrm{CD} 38^{\text {hi }}$ B cells in PBMCs compared with healthy individuals [7]. Our data also found a remarkable decrease in the frequency of $\mathrm{CD} 19^{+} \mathrm{CD} 24^{\mathrm{hi}} \mathrm{CD} 38^{\mathrm{hi}}$ Bregs in RA patients. Although the number of $\mathrm{CD} 19^{+} \mathrm{CD} 24^{\mathrm{hi}} \mathrm{CD} 38^{\mathrm{hi}}$ B cells was increased in SLE patients, they lacked the suppressive capacity due to their failure to produce IL-10 [12]. Previous studies showed that IL-10 production of human B cells was associated
A
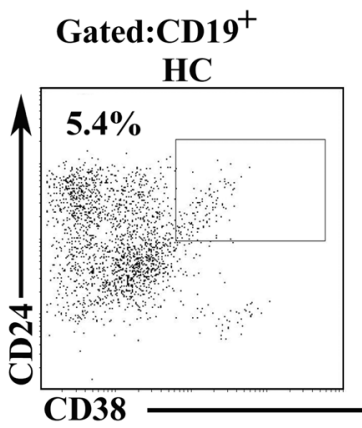

C

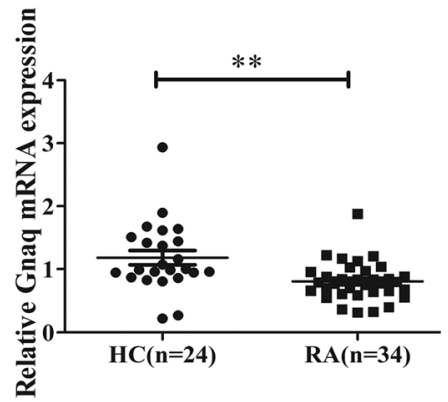

B

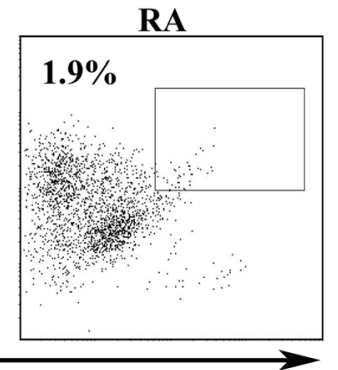

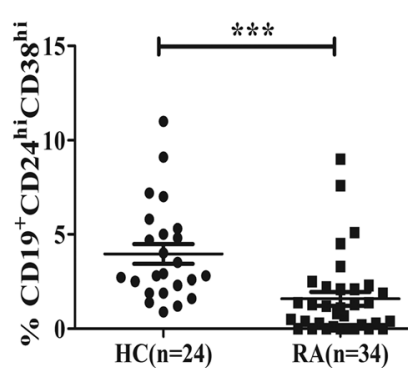

D

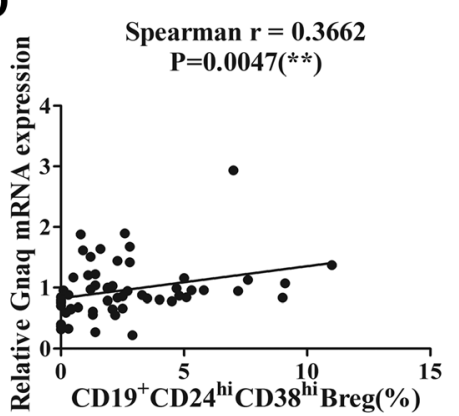

Fig. 6 Correlation of frequencies of $\mathrm{CD} 19^{+} \mathrm{CD} 24^{\text {hi }} \mathrm{CD} 38^{\text {hi }} \mathrm{B}$ cells with Gaq mRNA expression in PBMCs from RA patients. PBMCs isolated from patients with RA and healthy individuals stained with CD19, CD24, and CD38. Representative flow cytometry plots showed CD19 ${ }^{+}$CD24 ${ }^{\text {hi }}$ CD38 ${ }^{\text {hi }}$ B-cell subpopulations in PBMCs from healthy individuals $(n=24)$ and RA patients $(n=34)(\mathbf{a}$, representative images; b, statistical analysis). $\mathbf{c}$ Expression level of Gaq assessed by qPCR and normalized to $\beta$-actin in PBMCs from HC and RA patients. Mann-Whitney test compared data between two groups. $\mathbf{d}$ Correlation coefficient between Gaq expression and $\mathrm{CD} 19^{+} \mathrm{CD} 24^{\text {hi }} \mathrm{CD} 38^{\text {hi }}$ B-cell frequencies analyzed using the Spearman test $(n=58)$. ${ }^{* *} p<0.01,{ }^{* *} p<0.001$. Breg regulatory B cell, HC healthy controls, RA rheumatoid arthritis 
with the activation of STAT3 and ERK [37]. Our current findings showed that IL-10 production was also impaired in Bregs in the absence of Goq.

Activation of the ERK pathway is a common requirement for IL-10 expression by T cells, macrophages, and myeloid dendritic cells [32]. Abrogation of either ERK or p38 activation after TLR stimulation leads to a reduced IL-10 expression, which suggests that these two pathways might cooperate in TLR-induced IL-10 production [32]. Consistently, inhibition of PI3K, Erk1/2, or p38 MAPK significantly ablates the Breg differentiation in our study here. As expected, we found that the basal levels of phospho-PI3K, phospho-Erk1/2, and phospho-p38 MAPK in response to LPS were lower in $\mathrm{Gnaq}^{-1-}$ B cells than in WT B cells. These data suggest that Goq was involved in the differentiation of Bregs partly through regulation of PI3K, Erk1/2, or p38 MAPK signaling. That IL-10 can be induced by LPS in many cells has been demonstrated. However, we here observed no marked differences of TLR4 and MyD88 expression between B cells from WT and $\mathrm{Gnaq}^{-/-}$mice, which further confirms the regulation of Goq in the PI3K, Erk1/2, and p38 MAPK signaling pathways of Breg function.

In a previous study we demonstrated that $\mathrm{Gnaq}^{-/-}$chimeras could spontaneously develop manifestations of systemic autoimmune disease with high titer antinuclear antibody and inflammatory arthritis, and B cells from $\mathrm{Gnaq}^{-/-}$mice have an intrinsic survival advantage over

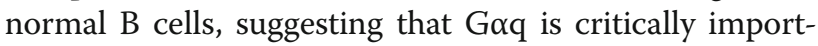
ant for maintaining control of peripheral B-cell tolerance induction and repressing autoimmunity [24]. However, the role of Goq in Breg regulation remains unknown. Actually, the percentage of Bregs was significantly lower in the spleen of $\mathrm{Gnaq}^{--}$mice. Consistent with the animal experiments, our data here showed a significant positive correlation between the frequency of $\mathrm{CD} 19^{+} \mathrm{CD} 24^{\mathrm{hi}} \mathrm{CD} 38^{\mathrm{hi}}$ Bregs and the expression of Goq mRNA in PBMCs from patients with RA and HC. Our current findings showed that Goq deficiency limited the differentiation of Bregs. Several studies demonstrated that Bregs were important for the generation and maintenance of Tregs [4]. Bregs could induce the differentiation of type 1 regulatory $\mathrm{T}$ (Tr1) cells [38, 39]. Moreover, Bregs might promote the differentiation of other type of regulatory T-cell subsets [40]. Consistent with prior studies, purified WT Bregs could convert $\mathrm{CD} 4^{+} \mathrm{CD} 25^{-} \mathrm{T}$ cells into Tregs, but this function of $\mathrm{Gnaq}^{-/-}$Bregs was impaired. Indeed, we also observed an impaired inhibition of T-cell expansion in $\mathrm{Gnaq}^{-/-}$Bregs. This might be the reason for impaired suppressive function of $\mathrm{Gnaq}^{-/-}$Bregs on $\mathrm{T}$-cell proliferation. Some studies suggested that CD40 mAb-stimulated $C D 1 d^{\text {hi }} \mathrm{CD}^{+}$B cells could not regulate T-cell proliferation in vitro [41]. TLRs and CD40 activation are well-characterized signals in Breg differentiation $[4,9]$. However, LPS but not CD40 activator can induce IL-10 secretion [36], which might be the reason for no effect on T-cell proliferation inhibition being observed.

\section{Conclusions}

Although we do not yet know whether Gaq deficiency in Bregs alone is sufficient to induce autoimmune disease, our work showed a critical intrinsic role for Goq in the maintenance of Breg differentiation and function. Furthermore, our data suggested that the regulation of Goq on Breg differentiation might occur partly via the PI3K, Erk1/2, and p38 MAPK signaling pathways. Our study here provides new insights into the mechanisms of Breg immune tolerance.

\section{Additional files}

\begin{abstract}
Additional file 1: Figure S1. Gaq deficiency promoted B cells to secrete inflammatory cytokines. (A-D) Splenic cells isolated from $\mathrm{Gnaq}^{-/-}$ mice and WT littermates and subjected to flow cytometry analysis after PMA, ionomycin, and BFA stimulation. Splenic cells stained with antimouse CD19, followed by intracellular staining with IFN- $\gamma$ and IL-17a. Representative images and statistical analysis of $\mathrm{CD} 19^{+} \mathrm{IFN}-\gamma^{+}$and $\mathrm{CD} 19^{+} \mathrm{IL}-$ 17a shown in (A, C) and (B, D) respectively. (E) Splenic B cells purified from WT and $\mathrm{Gnaq}^{-/-}$mice and stimulated with LPS for 0-10 min. Protein from cell lysates exacted and analyzed using western blot analysis. Phospho-STAT1 and STAT1 probed using specific antibodies individually. $\beta$-Tubulin used as control protein. (F) B cells isolated from the spleens of WT and $\mathrm{Gnaq}^{-1-}$ mice and stimulated with LPS for $48 \mathrm{~h}$, and then PMA, ionomycin, and BFA added for last $5 \mathrm{~h}$. After culture, cells stained with anti-mouse CD19, followed by intracellular staining with IL-17a. Results represent mean \pm SD per group ( $n=6-8$ mice/group). Student's $t$ test analyzed statistical difference. Data representative of three independent experiments. ${ }^{*} p<0.05,{ }^{* *} p<0.01$ (DOCX $1303 \mathrm{~kb}$ )

Additional file 2: Figure S2. Gaq deficiency impaired anti-inflammatory cytokines in Bregs. B cells isolated from spleen of WT and $\mathrm{Gnaq}^{-1-}$ mice and stimulated with LPS for $48 \mathrm{~h}$, and then culture supernatant was harvested and subjected to analyze levels of IL-35 (A) and TGF- $\beta$ (B) by ELISA. Results represent mean \pm SD per group ( $n=6-8$ mice/group). Student's $t$ test analyzed statistical difference. Data representative of three independent experiments. ${ }^{* *} p<0.01$ (DOCX $1000 \mathrm{~kb}$ )
\end{abstract}

\section{Abbreviations}

Breg: Regulatory B cell; EAE: Experimental autoimmune encephalitis; Erk1/ 2: Extracellular regulated protein kinases 1/2; G protein: Guanine nucleotidebinding protein; GPCR: G protein-coupled receptor; HC: Healthy controls; IL: Interleukin; LPS: Lipopolysaccharide; MyD88: Myeloid differentiation primary response 88; p38 MAPK: p38 mitogen-activated protein kinase; PBMC: Peripheral blood mononuclear cell; PI3K: PI3 kinase; qPCR: Quantitative real-time PCR; RA: Rheumatoid arthritis; SD: Standard deviation; SLE: Systemic lupus erythematosus; TGF- $\beta$ : Transforming growth factor beta; Th1: Thelper 1; Th17: T helper 17; TLR: Toll-like receptor; Treg: Regulatory T cell; WT: Wild type

\section{Acknowledgements}

The authors thank Dr Junhui Zhang and Xue Zhao for the genotyping of $\mathrm{Gnaq}^{-1-}$ mice.

\section{Funding}

This work was partly supported by the National Natural Science Foundation of China (NFSC, No. 81701556, U1605223, 81671544, and 8151407), the National Key Basic Research Program of China (973 Program, No. 
2014CB541903), and the Xiamen Science and Technology Bureau (Project No. 3502Z20174066, 3502Z20164006).

\section{Availability of data and materials}

The datasets used and/or analyzed during the current study are available from the corresponding author on reasonable request.

\section{Authors' contributions}

$Y H, X Y, L D$, and GS conceived and designed this study, were responsible for integrity of the work, interpretation of data, and drafting the manuscript, and gave final approval to the version of the paper to be published. YLi, CZ, and HQ participated in clinical material collection, cell culture, and ELISA test. YH and LD performed flow cytometric experiments and analysis. XY and YLiu performed QPCR and western blot analysis. JX helped with statistical analysis of the data. All authors reviewed and approved the submission.

\section{Ethics approval}

Animal studies were approved by the institutional animal care committee of Xiamen University (Xiamen, Fujian, China). Patient consent was obtained. This study was approved by the Ethics Committee of the First Affiliated Hospital of Xiamen University in accordance with the World Medical Association Declaration of Helsinki.

\section{Consent for publication}

Not applicable.

\section{Competing interests}

The authors declare that they have no competing interests.

\section{Publisher's Note}

Springer Nature remains neutral with regard to jurisdictional claims in published maps and institutional affiliations.

\section{Author details}

'Department of Rheumatology and Clinical Immunology, The First Affiliated Hospital of Xiamen University, Xiamen, China. ${ }^{2}$ Ningbo City Medical Treatment Center Lihuili Hospital, No. 57 Xingning Road, Ningbo 315000, China

\section{Received: 5 February 2018 Accepted: 23 July 2018}

Published online: 24 August 2018

\section{References}

1. Lund FE, Randall TD. Effector and regulatory B cells: modulators of CD4+ T cell immunity. Nat Rev Immunol. 2010;10(4):236-47.

2. Wolf SD, Dittel BN, Hardardottir F, Janeway CA Jr. Experimental autoimmune encephalomyelitis induction in genetically B cell-deficient mice. J Exp Med. 1996;184(6):2271-8.

3. Fillatreau S, Sweenie CH, McGeachy MJ, Gray D, Anderton SM. B cells regulate autoimmunity by provision of IL-10. Nat Immunol. 2002;3(10):944-50.

4. Mauri C, Bosma A. Immune regulatory function of B cells. Annu Rev Immunol. 2012:30:221-41.

5. Berthelot JM, Jamin C, Amrouche K, Le Goff B, Maugars Y, Youinou P. Regulatory $B$ cells play a key role in immune system balance. Joint Bone Spine. 2013;80(1):18-22.

6. Carter NA, Vasconcellos R, Rosser EC, Tulone C, Munoz-Suano A, Kamanaka M, Ehrenstein MR, Flavell RA, Mauri C. Mice lacking endogenous IL-10producing regulatory $B$ cells develop exacerbated disease and present with an increased frequency of Th1/Th17 but a decrease in regulatory T cells. J Immunol. 2011;186(10):5569-79.

7. Flores-Borja F, Bosma A, Ng D, Reddy V, Ehrenstein MR, Isenberg DA, Maur C. CD19+CD24hiCD38hi B cells maintain regulatory T cells while limiting TH1 and TH17 differentiation. Sci Transl Med. 2013:5(173):173ra123.

8. Bosma A, Abdel-Gadir A, Isenberg DA, Jury EC, Mauri C. Lipid-antigen presentation by $\mathrm{CD} 1 \mathrm{~d}(+) \mathrm{B}$ cells is essential for the maintenance of invariant natural killer T cells. Immunity. 2012;36(3):477-90.

9. Rosser EC, Mauri C. Regulatory B cells: origin, phenotype, and function. Immunity. 2015;42(4):607-12.

10. Candando KM, Lykken JM, Tedder TF. B10 cell regulation of health and disease. Immunol Rev. 2014;259(1):259-72.
11. Ramgolam VS, Sha Y, Marcus KL, Choudhary N, Troiani L, Chopra M, Markovic-Plese S. B cells as a therapeutic target for IFN-beta in relapsingremitting multiple sclerosis. J Immunol. 2011;186(7):4518-26.

12. Blair PA, Norena LY, Flores-Borja F, Rawlings DJ, Isenberg DA, Ehrenstein MR, Mauri C. CD19(+)CD24(hi)CD38(hi) B cells exhibit regulatory capacity in healthy individuals but are functionally impaired in systemic lupus erythematosus patients. Immunity. 2010;32(1):129-40.

13. Kalampokis I, Venturi GM, Poe JC, Dvergsten JA, Sleasman JW, Tedder TF. The regulatory $B$ cell compartment expands transiently during childhood and is contracted in children with autoimmunity. Arthritis Rheumatol. 2017; 69(1):225-38.

14. Neves SR, Ram PT, lyengar R. G protein pathways. Science. 2002;296(5573): 1636-9.

15. Hubbard KB, Hepler JR. Cell signalling diversity of the Gqalpha family of heterotrimeric G proteins. Cell Signal. 2006;18(2):135-50.

16. Wettschureck N, Offermanns S. Mammalian G proteins and their cell type specific functions. Physiol Rev. 2005;85(4):1159-204.

17. Offermanns S, Toombs CF, Hu YH, Simon Ml. Defective platelet activation in G alpha(q)-deficient mice. Nature. 1997;389(6647):183-6.

18. Offermanns S, Hashimoto K, Watanabe M, Sun W, Kurihara H, Thompson RF, Inoue $Y$, Kano M, Simon Ml. Impaired motor coordination and persistent multiple climbing fiber innervation of cerebellar Purkinje cells in mice lacking Galphaq. Proc Natl Acad Sci U S A. 1997:94(25):14089-94.

19. Wettschureck N, Moers A, Wallenwein B, Parlow AF, Maser-Gluth C, Offermanns S. Loss of $\mathrm{Gq} / 11$ family $\mathrm{G}$ proteins in the nervous system causes pituitary somatotroph hypoplasia and dwarfism in mice. Mol Cell Biol. 2005; 25(5):1942-8.

20. Borchers MT, Biechele T, Justice JP, Ansay T, Cormier S, Mancino V, Wilkie TM, Simon MI, Lee NA, Lee JJ. Methacholine-induced airway hyperresponsiveness is dependent on Galphaq signaling. Am J Physiol Lung Cell Mol Physiol. 2003;285(1):L114-20.

21. Borchers MT, Justice PJ, Ansay T, Mancino V, McGarry MP, Crosby J, Simon $\mathrm{Ml}$, Lee NA, Lee JJ. Gq signaling is required for allergen-induced pulmonary eosinophilia. J Immunol. 2002;168(7):3543-9.

22. Shi G, Partida-Sanchez S, Misra RS, Tighe M, Borchers MT, Lee JJ, Simon MI, Lund FE. Identification of an alternative G\{alpha\}q-dependent chemokine receptor signal transduction pathway in dendritic cells and granulocytes. J Exp Med. 2007:204(11):2705-18

23. Ngai J, Methi T, Andressen KW, Levy FO, Torgersen KM, Vang T, Wettschureck N, Tasken K. The heterotrimeric G-protein alpha-subunit Galphaq regulates TCR-mediated immune responses through an LCkdependent pathway. Eur J Immunol. 2008;38(11):3208-18.

24. Misra RS, Shi G, Moreno-Garcia ME, Thankappan A, Tighe M, Mousseau B, Kusser K, Becker-Herman S, Hudkins KL, Dunn R, et al. G alpha q-containing $G$ proteins regulate $B$ cell selection and survival and are required to prevent B cell-dependent autoimmunity. J Exp Med. 2010;207(8):1775-89.

25. He Y, Huang Y, Tu L, Luo J, Yu B, Qian H, Duan L, Shi G. Decreased Galphaq expression in T cells correlates with enhanced cytokine production and disease activity in systemic lupus erythematosus. Oncotarget. 2016;7(52):85741-9.

26. Arnett FC, Edworthy SM, Bloch DA, McShane DJ, Fries JF, Cooper NS, Healey LA, Kaplan SR, Liang MH, Luthra HS, et al. The American Rheumatism Association 1987 revised criteria for the classification of rheumatoid arthritis. Arthritis Rheum. 1988:31(3):315-24

27. Aletaha D, Neogi T, Silman AJ, Funovits J, Felson DT, Bingham CO 3rd, Birnbaum NS, Burmester GR, Bykerk VP, Cohen MD, et al. 2010 rheumatoid arthritis classification criteria: an American College of Rheumatology/ European League Against Rheumatism collaborative initiative. Arthritis Rheum. 2010;62(9):2569-81.

28. Yanaba K, Bouaziz JD, Matsushita T, Tsubata T, Tedder TF. The development and function of regulatory B cells expressing IL-10 (B10 cells) requires antigen receptor diversity and TLR signals. J Immunol. 2009;182(12):7459-72.

29. Lampropoulou V, Hoehlig K, Roch T, Neves P, Calderon Gomez E, Sweenie $\mathrm{CH}$, Hao $Y$, Freitas AA, Steinhoff U, Anderton SM, et al. TLR-activated B cells suppress T cell-mediated autoimmunity. J Immunol. 2008;180(7):4763-73.

30. Neves P, Lampropoulou V, Calderon-Gomez E, Roch T, Stervbo U, Shen P, Kuhl AA, Loddenkemper C, Haury M, Nedospasov SA, et al. Signaling via the MyD88 adaptor protein in B cells suppresses protective immunity during Salmonella typhimurium infection. Immunity. 2010:33(5):777-90.

31. Lattin J, Zidar DA, Schroder K, Kellie S, Hume DA, Sweet MJ. G-proteincoupled receptor expression, function, and signaling in macrophages. J Leukoc Biol. 2007;82(1):16-32. 
32. Saraiva $M, O$ 'Garra $A$. The regulation of IL-10 production by immune cells. Nat Rev Immunol. 2010;10(3):170-81.

33. Katz SI, Parker D, Turk JL. B-cell suppression of delayed hypersensitivity reactions. Nature. 1974:251(5475):550-1.

34. Neta R, Salvin SB. Specific suppression of delayed hypersensitivity: the possible presence of a suppressor $B$ cell in the regulation of delayed hypersensitivity. J Immunol. 1974;113(6):1716-25.

35. Mizoguchi A, Mizoguchi E, Takedatsu H, Blumberg RS, Bhan AK. Chronic intestinal inflammatory condition generates IL-10-producing regulatory B cell subset characterized by CD1d upregulation. Immunity. 2002;16(2):219-30.

36. Tedder TF. B10 cells: a functionally defined regulatory B cell subset. J Immunol. 2015;194(4):1395-401.

37. Liu BS, Cao Y, Huizinga TW, Hafler DA, Toes RE. TLR-mediated STAT3 and ERK activation controls IL-10 secretion by human B cells. Eur J Immunol. 2014:44(7):2121-9.

38. Sayi A, Kohler E, Toller IM, Flavell RA, Muller W, Roers A, Muller A. TLR-2activated B cells suppress helicobacter-induced preneoplastic gastric immunopathology by inducing T regulatory-1 cells. J Immunol. 2011;186(2): 878-90.

39. Ahangarani RR, Janssens W, VanderElst L, Carlier V, VandenDriessche $T$, Chuah M, Weynand B, Vanoirbeek JA, Jacquemin M, Saint-Remy JM. In vivo induction of type 1-like regulatory $T$ cells using genetically modified B cells confers long-term IL-10-dependent antigen-specific unresponsiveness. J Immunol. 2009;183(12):8232-43.

40. Wei B, Velazquez P, Turovskaya O, Spricher K, Aranda R, Kronenberg M, Birnbaumer $L$, Braun J. Mesenteric B cells centrally inhibit CD4+ T cell colitis through interaction with regulatory T cell subsets. Proc Natl Acad Sci U S A. 2005;102(6):2010-5.

41. Matsushita T, Horikawa M, Iwata Y, Tedder TF. Regulatory B cells (B10 cells) and regulatory $T$ cells have independent roles in controlling experimental autoimmune encephalomyelitis initiation and late-phase immunopathogenesis. J Immunol. 2010;185(4):2240-52.

Ready to submit your research? Choose BMC and benefit from:

- fast, convenient online submission

- thorough peer review by experienced researchers in your field

- rapid publication on acceptance

- support for research data, including large and complex data types

- gold Open Access which fosters wider collaboration and increased citations

- maximum visibility for your research: over $100 \mathrm{M}$ website views per year

At $\mathrm{BMC}$, research is always in progress.

Learn more biomedcentral.com/submissions 